\title{
O SENTIDO DA ARTE: O CASO DO CENTRO CULTURAL Banco DO BRASIL $-\mathbb{R} I$
}

\author{
Rafael Pereira Oliveira* \\ Marcelo Milano Falcão Vieira** \\ Rosimeri Carvalho da Silva***
}

Resumio

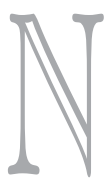

este artigo apresenta-se uma análise, por meio da abordagem sociológica do poder, das relações que se estabelecem no campo da cultura quando se evidencia o imbricamento entre distintas motivações e lógicas de ação. O estudo é realizado sobre um episódio ocorrido na cidade do Rio de Janeiro, que se apresenta como um caso emblemático e bastante significativo de como se configuram e se expressam os diferentes poderes no campo da cultura. O caso analisado trata da retirada de uma obra de arte da exposição "Erótica - os sentidos na arte", promovida pelo Centro Cultural Banco do Brasil (CCBB), no Rio de Janeiro, por decisão da empresa patrocinadora da mostra. A decisão foi tomada a partir da pressão exercida por uma entidade católica conservadora denominada Opus Christi. Argumenta-se que na base do episódio encontra-se uma disputa pela definição do sentido da arte. Desvela-se a estrutura de poder existente entre o financiador e o realizador, no caso o Banco do Brasil e o CCBB, a qual demonstra a fragilidade das instituições responsáveis pelas políticas públicas para a cultura, resultando em aumento de importância do capital econômico em detrimento do capital cultural.

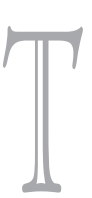

\begin{abstract}
ABSTIRACT
he aim of this paper is to analyze the relations established in the field of culture, due to the disputes between actors with distinct motivations and logics of action. In order to perform the analysis a sociological approach of power was chosen. The study is based on an event occurred in the city of Rio de Janeiro, which presents itself as an emblematic and very significant case of how different powers in the field of culture are structured and expressed. The case analyzed is related to the removal of a work of art from the exposition "Erotic - the senses if the art", promoted by Cultural Center of Bank of Brasil" (CCBB), in Rio de Janeiro, due to the pressions imposed by a catholic conservative group called Opus Christi. The argument is that the reason why this event took place is related to a dispute over the definition on the sense of art. The current power structure between financiers and financed is unveiled, in this case, Bank of Brasil and CCBB, which demonstrate the weakness of the institutions responsible for cultural public policies, resulting in an increase of economic capital to the detriment of cultural capital.
\end{abstract}

\footnotetext{
* Pesquisador do Observatório da Realidade Organizacional - CPGA/UFSC

** Prof. EBAPE/FGV

*** Profa CPGA/UFSC
} 
(...) desde que o critério de autenticidade não mais se aplica à produção artística, toda a função da arte é subvertida. Em lugar de repousar sobre o ritual, ela se funda agora sobre uma outra forma da práxis: a política.

Walter Benjamin

o clássico "A obra de arte na época de sua reprodutibilidade técnica", Walter Benjamin (2002) discute a função da arte no contexto das mudanças tecnológicas ocorridas no início do século XX. O autor conclui que, mesmo com a emancipação da obra de arte de uma dependência imposta por sua função ritual, ela não deixa de ser objeto de culto e o seu sentido continua sendo definido por meio de disputas entre novos e velhos atores. Neste início de século XXI, um episódio traz à tona esse debate. Na arena, o mecenas, a Igreja, os artistas, o Estado e o mercado disputam o direito de definir qual o sentido da arte.

No período de 21 de fevereiro a 30 de abril de 2006, foi realizada a exposição "Erótica - os sentidos na arte", no Centro Cultural Banco do Brasil (CCBB), no Rio de Janeiro. De acordo com o curador, Tadeu Chiarelli,

a mostra apresenta uma visão abrangente e desmistificadora das questões relativas à sexualidade através de representativas criações. Revela, sobretudo, como o erotismo evoluiu esteticamente como tema artístico e artesanal nas mais variadas regiões e épocas. Mais de 100 obras de artistas como Anita Malfatti, Pablo Picasso, Ismael Nery, Ivan Serpa, Vicente do Rego Monteiro, Antônio Gomide, Eliseu Visconti, Lygia Pape, Alair Gomes, Auguste Rodin, Francis Picabia, Almeida Júnior, Paul Gauguin entre outros, se juntam a objetos criados por anônimos para contribuir com a disseminação da cultura dos povos ao tempo em que nega a banalização por vezes associada ao instinto vital do sexo (BANCO DO BRASIL

- CULTURA, 2006).

Após permanência no CCBB/São Paulo e decorridos dois meses de sua inauguração no Rio de Janeiro, no dia 19 de abril de 2006, a obra "Desenhando com Terços", da artista Márcia X (1959-2005), ilustrada a seguir, foi retirada da exposição por ordem da diretoria do Banco do Brasil, patrocinador da mostra. A obra é um fotograma onde se vê o desenho de dois pênis cruzados em forma de $X$, realizados com terços diretamente sobre o papel fotográfico. Ressalta-se que a mostra apresentava "obras das mais distintas regiões do planeta, pertencentes às mais diversas civilizações, produzidas em momentos históricos os mais diferentes e que possuem como ponto em comum expressões singulares do erotismo na arte"1.

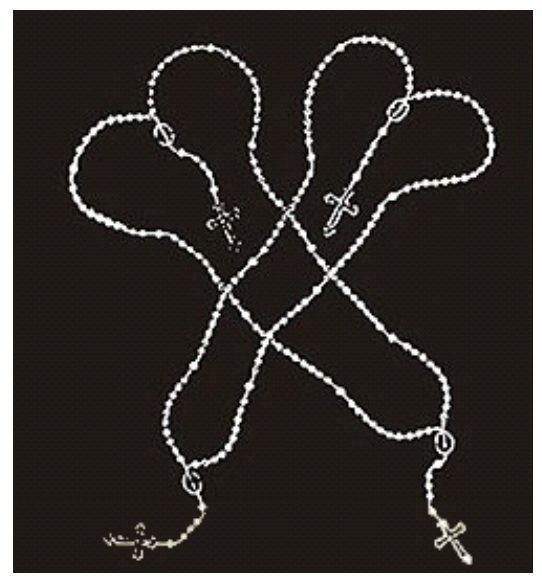

"Desenhando com terços" - Márcia X

\footnotetext{
${ }^{1}$ Trecho do texto de apresentação da exposição presente no programa impresso distribuído ao público, assinado pelo curador da mostra, Tadeu Chiarelli.
} 
A decisão da diretoria do Banco do Brasil deu-se a partir de pressões da organização católica conservadora chamada Opus Christi, que alegou falta de respeito ao sentimento religioso ${ }^{2}$, utilizando diversos mecanismos de pressão para a retirada da obra. Nenhuma dessas ações, entretanto, parece refletir a percepção espontânea das 120 mil pessoas que visitaram a exposição, entre São Paulo e Rio, sem que se registrasse alguma manifestação de repúdio.

Neste artigo, discutimos as relações que se estabelecem na disputa pelo "sentido da arte", o que acaba por revelar a estrutura de poder existente entre o financiador e o realizador, no caso o Banco do Brasil e o CCBB. Para análise desse episódio utilizamos a abordagem sociológica do poder de Pierre Bourdieu, que nos permite evidenciar o imbricamento entre distintas motivações e lógicas de ação no campo da cultura, ou seja, no que o autor chamou de sistema de produção e circulação de bens simbólicos (BOURDIEU, 1993). Este fato apresenta-se como emblemático na compreensão das relações que se estabelecem entre arte, mercado, religião e políticas públicas. Para a análise de tais relações, aqui chamadas de "jogos de poder" (BOURDIEU, 1968), definiremos primeiro a arena aonde se dá esta disputa, a seguir identificaremos os atores-jogadores envolvidos, suas lógicas de ação e recursos de poder e a dinâmica dessas relações.

Nossa interpretação foi construída utilizando informações e relatos disponíveis na imprensa escrita e na internet, de 20 de abril a 26 de maio, complementados com observação direta de um dos autores, a qual foi realizada por meio do acompanhamento das manifestações dos artistas que aconteceram nas semanas seguintes à retirada da obra.

\section{A Aremal}

O espaço social onde os atores envolvidos neste episódio interagem constitui-se uma arena, na qual distintos interesses estão em disputa, configurando o que Bourdieu (2004a, p.52) chamou de campo de poder. Trata-se de um "espaço de relações de força" que se estabelecem em um campo específico entre os atores providos de um dos diferentes tipos de capital (cultural, econômico ou político, por exemplo). Cada campo específico possui suas próprias leis de funcionamento e é constituído pelas posições que os atores que concorrem pela legitimidade ocupam em um dado momento e pelas relações objetivas entre eles. O que está em jogo é a conservação ou a transformação da estrutura a partir da luta pela manutenção ou melhoria de suas posições nos respectivos campos (BOURDIEU, 2004a).

O campo não é uma estrutura fixa, mas uma estrutura que é composta pela posição dos atores (indivíduos ou grupos) que "podem ser descritos como forças que se dispondo, opondo e compondo, Ihe conferem sua estrutura específica num dado momento do tempo" (BOURDIEU, 1968, p. 105). Ao mesmo tempo em que esta estrutura de que fazem parte os constitui, é por eles constituída. A posição de cada ator no campo é definida pela quantidade de determinado capital que detém e que pode ser convertido, nos campos de poder, em outro tipo de capital (BOURDIEU, 2004a).

Os campos não são homogêneos e o conflito lhes é inerente e se estabelece entre os atores que o dominam, por monopolizarem o capital específico daquele campo. A dominação ocorre pela autoridade, um tipo de violência simbólica que "é julgada legítima dentro de cada campo" (THIRY-CHERQUES, 2006, p. 37).

A arena objeto de nossa análise pode ser compreendida pela abordagem que Bourdieu (1993) dá ao sistema de produção e circulação de bens simbólicos. Esse sistema se estrutura a partir de relações objetivas entre diferentes instâncias envolvidas na produção, reprodução e difusão desses bens. A relação de oposição entre as lógicas da produção restrita e da produção em larga escala estruturam o sistema onde o poder exercido se caracteriza como invisível, simbólico, difuso,

2 Jornal do Brasil, 21 abr. 2006, p. 08. 
que encharca todas as estruturas e estabelece as dinâmicas das relações (BOURDIEU, 2004b).

O embate básico que estrutura o sistema e cria os diversos campos de poder relaciona-se à função da arte e estabelece duas posições antagônicas. Uma acredita na não utilidade da obra de arte; na expressão de Hannah Arendt, é única e não deve ter outra finalidade que não seja ela mesma. Ou seja, vê a arte como sendo algo não intercambiável e não passível de "igualação através de um denominador comum como o dinheiro " (ARENDT, 1981, p. 180). A segunda posição vê a arte como meio de expressão de outros valores culturais. Nessa visão, a arte é convocada para promover uma determinada idéia de civilização, "perde seu valor de uso e assume um valor de troca, como qualquer outra coisa ou bem", num processo que tem sido denominado comoditização (COELHO, 2004, p.46).

$\mathrm{Na}$ defesa pela inutilidade dos objetos de arte está o argumento de que a arte atingiu sua autonomia, sobrevivendo à separação da religião, da magia e do mito (ARENDT, 1981). Esta autonomia é questionada por diversos autores. Benjamin (2002) afirma que a arte sempre teve e mantém a função essencial de servir ao culto. Na antiguidade, surge ligada aos rituais mágicos, depois religiosos e, com o Renascimento, transforma-se no culto à beleza, com o ritual sendo estabelecido ora pelos circuitos acadêmicos, ora pela corte. O processo de criação sempre esteve atrelado a algum tipo de dependência social que imputa à obra de arte um valor, denominado também de aura.

Bourdieu (2001) acha que com o surgimento das técnicas de reprodutibilidade advindas da Revolução Industrial, a arte obtém uma relativa autonomia dos meios tradicionais (Igreja, academia ou mecenas), mas vê-se engendrada num mercado impessoal que vai aos poucos lhe impondo novas restrições.

Como reação a este movimento, os artistas proclamam a concepção de uma arte pura, que recusa desempenhar qualquer papel essencial. Passam a resignificá-la e a sacralizam como objeto capaz de ser exposto, admirado e novamente cultuado (BENJAMIN, 2002).

O campo da produção restrita (ou erudita) se desenvolve a partir dessa "pretensão à autonomia" exigida pelo artista, e tem como lógica de funcionamento o estímulo à liberdade de criação e à valorização da obra de arte pelas suas exigências intrínsecas. Trata-se de um modo de produção que se destina a um público dotado de disposição estética (BOURDIEU, 1983), uma competência específica que dá a ele condições para uma apropriação legítima da obra de arte e que coloca o público em geral fora do jogo, num esforço de separar o universo do artista do mundo cotidiano.

Entre as práticas exercidas no sistema de produção e circulação de bens simbólicos estão as museais, que envolvem, segundo o Conselho Internacional de Museus (ICOM) ${ }^{3}$, coleta, conservação, estudo e exploração dos testemunhos materiais do homem e do seu meio ambiente. Ao incorporar a noção de interdisciplinaridade, a museologia contemporânea tem procurado alargar a noção de patrimônio e redefinir o objeto museológico (MOUTINHO, 1993). Essa nova realidade é que permite incluir no campo museal uma organização como o CCBB, que apesar de não preencher todos os requisitos de um museu tradicional é aceita como ator importante no campo e nas relações que nele se estabelecem.

A maioria das organizações culturais (nas quais se inserem as museais), por seu caráter social, é, predominantemente, atrelada a investimentos públicos. Voltadas à promoção, expressão e difusão da cultura, são fortemente influenciadas pela atuação do Estado no campo. Bourdieu (2004b) chama a atenção para o papel fundamental do Estado na regulação do funcionamento do campo cultural, seja por meio de intervenções financeiras, seja através de intervenções jurídicas, em virtude da sua capacidade de concentrar um conjunto de recursos materiais e simbólicos.

${ }^{3}$ Estatutos do Conselho Internacional de Museus (ICOM). 
Na tentativa de compreender melhor, apresentamos, a seguir, uma síntese histórica da atuação do Estado brasileiro no campo da cultura, a partir da "Era Vargas" (décadas de 30 e 40), quando o Estado passou a assumir forte presença na construção de políticas para o setor e no controle da produção cultural do país. Nesse período, importantes instituições culturais foram criadas, como o Serviço do Patrimônio Histórico e Artístico Nacional (mais tarde denominado IPHAN). A percepção da necessidade de construção de uma identidade nacional fez com que o governo se aproximasse dos intelectuais modernistas, na busca da elaboração de uma cultura nacional que negasse o regionalismo em prol da brasilidade. 0 discurso dos "modernistas" estava voltado para a democratização do acesso aos bens culturais, mas, na prática, as ações ficaram limitadas à valorização do patrimônio de origem européia, ou seja, um viés civilizador, que excluía a diversidade de manifestações formadoras da cultura brasileira.

A influência desses intelectuais na construção de políticas culturais se fez sentir para além da "Era Vargas", por todo o período democrático (1946 a 1964), quando houve a manutenção do modelo de forte intervenção do Estado no campo da cultura.

Apesar das relações entre cultura e Estado terem sido sensivelmente alteradas a partir do golpe militar de 1964, o sistema paternalista e patrimonialista construído no período anterior se manteve. Realizou-se um projeto controlado para estimular a produção cultural, a partir da criação de diversas instituições estatais, como a FUNARTE e a EMBRAFILME. No bojo do desenvolvimento do capitalismo brasileiro, ocorreu o desenvolvimento de um mercado de bens simbólicos que passou a direcionar as atenções das políticas públicas para a área da cultura.

Os anos 80 foram marcados pela forte crise econômica que se instalou no país e que afetou todas as políticas sociais. Esse contexto, aliado à volta da democracia, formou a base do que veio a ser o novo modelo de gestão da cultura, inaugurado no governo Sarney. Apesar do surgimento de uma nova instância administrativa para a cultura, o Ministério da Cultura (MinC) - em 1985 -, e da intenção de estabelecer um diálogo mais franco com a sociedade, o período Sarney foi marcado por uma diminuição da responsabilidade do Estado sobre a gestão da cultura, com carência de recursos humanos, físicos e financeiros. É desse período a introdução da política de incentivo fiscal para contribuintes que apoiassem ações na área da cultura, por meio da Lei Sarney (1986). Esta fundamentava-se na possibilidade de estimular as organizações privadas a desenvolverem suas próprias políticas culturais, mas também calcada na necessidade de buscar recursos públicos antes que os mesmos chegassem ao Tesouro e fossem absorvidos pelas demandas advindas de uma dívida externa elevada e de um controle austero do gasto público.

As importantes contribuições da Constituição de 1988 para a agenda social ainda não tinham sido sentidas quando, em 1990, o governo Collor assumiu a presidência promovendo uma ampla desconstrução das instituições culturais brasileiras. Este governo trouxe para a agenda política nacional o tema da reforma do Estado, baseada numa concepção neoliberal que buscava a redução do tamanho do Estado com substituição pelo mercado sempre que possível, em prol da agilidade e eficiência (FLEURY, 2001).

Em tal cenário, é implantada a Lei Rouanet, no final de 1991, que lança as bases de um programa de apoio à cultura calcado em três mecanismos (FNC, FICART e Incentivo Fiscal), os quais buscavam contemplar a diversidade de dinâmicas das práticas culturais. No entanto, ao ser implementada, nos anos seguintes, se passou a valorizar cada vez mais o mecanismo de incentivo fiscal em detrimento dos outros.

Essa perspectiva foi aprofundada a partir de 1995, com o início do mandato do presidente Fernando Henrique Cardoso ( $F H C)$, que realizou uma extensa reforma administrativa do Estado brasileiro (Plano Bresser) com a delegação de competências para o setor privado, o "terceiro setor", Estados e Municípios, sem garantir a efetiva participação social. Esta foi instrumentalizada e subjugada à lógica 
mercantil vigente. Conforme afirmam Andrade e Silva (2006), surge uma nova relação entre Estado, mercado e sociedade civil, com o primeiro sendo moldado pelo segundo, ao invés do contrário.

O mecanismo de incentivo fiscal da Lei Rouanet foi o principal instrumento de política cultural pública utilizado na gestão de oito anos de FHC, "seja na utilização da estrutura e dos funcionários do Ministério da Cultura, seja na divulgação massiva de seus instrumentos [...] como fonte de recursos para a produção cultural" (OLIVIERI, 2004, p.163).

Ao mesmo tempo em que o sistema vigente durante o período FHC apresentava-se como "participativo" e "descentralizado", por prometer que a decisão fosse compartilhada entre Estado, Sociedade Civil e Mercado, o modelo acabou por reproduzir a estrutura de desigualdades da sociedade e da economia, observável na concentração de investimentos nas regiões Sudeste e Sul, em áreas e manifestações culturais mais consagradas e na predominância da lógica do mercado na confecção dos projetos.

Para garantir a maciça participação da iniciativa privada no processo, foram oferecidos abatimentos de até $100 \%$ ao contribuinte-patrocinador, em diversas áreas, o que estimulou a apropriação desse mecanismo como ferramenta de marketing pelos incentivadores. Estes passaram a utilizar recursos públicos para desenvolver ações de comunicação e, também, a ditar os rumos das políticas públicas para a cultura, conformando os projetos culturais às suas necessidades.

O governo Lula introduziu uma nova orientação política no governo federal, com o foco no cidadão e na redução das desigualdades regionais e sociais, a qual refletiu em mudanças na gestão da cultura, que passou a ser encarada numa dimensão mais ampla e compreendida como elemento importante do processo de desenvolvimento. Nesse sentido, houve uma democratização do acesso aos recursos, bens, produtos e serviços culturais. No entanto, a acomodação do mercado ao modelo de incentivo fiscal, acrescido do acúmulo de poder nas mãos dos intermediários culturais (agentes e captadores de recursos) e da pressão das empresas patrocinadoras refletiram na manutenção do sistema de incentivo fiscal como mecanismo estratégico da gestão das políticas culturais.

A primazia da política de incentivos fiscais tem gerado diversas distorções, como, por exemplo, a dificuldade na captação de recursos para a manutenção ou ampliação do acervo dos museus. Sem recursos públicos diretos para projetos que envolvam o acervo, as instituições museológicas necessitam concorrer com grandes eventos (circulação de exposições, bienais, entre outros) na busca de empresas que, na maioria das vezes, preferem vincular suas marcas à visibilidade de um evento que à doação (ou restauro) de uma obra.

Santos (2004), de acordo com sua pesquisa, afirma que, dentre as diversas instituições museológicas, aquelas que estão voltadas para a arte são as que têm maior poder de obter patrocínio de empresas privadas. Tal constatação culmina com a preocupação levantada por Meneses (2002, p. 38), que ele chama de "Disneyficação" dos museus, ou seja, estes deixam de ser espaços de contradição e inquietação para reproduzirem o já conhecido, "mas projetado sob formas diversas, sem, porém, alterar a substância do mesmo, de si próprio, da própria identidade (...)." São espaços que, para atrair novos investimentos, passam a reproduzir ações orientadas para o espetáculo, privilegiando a lógica econômica às necessidades culturais.

\section{Os Iogadlores e as $\mathbb{R} e g r$ ans}

Os jogadores não são livres para controlar o resultado de suas ações, pois participam de um jogo no qual os outros limitam, anulam ou amplificam a eficácia da própria ação (MATUS, 1996, p.14).

Para Matus (1996), o ator social é participante de um jogo, produtor e produto do sistema social. Possui um projeto que, mesmo inconsciente, orienta 
sua ação. Pode ser um "ator-pessoa" ou um "ator-grupo", mas sempre um ator organizado de forma "estável", que Ihe garanta atuar com o peso de um coletivo. "Além disso, deve-se considerar que num jogo social não participam somente atores, mas também a população não organizada, indivíduos etc" (MATUS, 1996, p.205).

O jogador não joga sozinho, mas em interação de cooperação ou confronto com o outro. Para solucionar problemas decorrentes dessas interações, estabelece estratégias que são como "planos de jogo" (MATUS, 1996).

Se, para Matus (1996), o ator social é um "sujeito criativo", que não segue leis, tendo um comportamento imprevisível, para Bourdieu (2001), as regras da disputa por posição são definidas pelo habitus. Thiry-Cherques (2006, p.33), ao analisar o pensamento de Bourdieu, conclui que "habitus é um sistema de disposições, modos de perceber, de sentir, de fazer, de pensar, que nos levam a agir de determinada forma em uma circunstância dada. (...) São as rotinas corporais e mentais inconscientes, que nos permitem agir sem pensar." O habitus é tanto individual quanto coletivo, e está entre a estrutura e a ação. Gera uma lógica, ao mesmo tempo em que é gerado pela lógica do campo (THIRY-CHERQUES, 2006).

Diante disso, podemos afirmar que a lógica de ação de um ator social se estabelece na relação entre a lógica do campo (ou o habitus coletivo), a posição em que o ator ocupa nele (ou o quanto de capital ele acumula) e o seu habitus individual (que é estruturado e estruturante). Essa relação de mão dupla é que capacita a compreensão de que o habitus determina as posições no campo, ao mesmo tempo em que tais posições é que o determinam.

$\mathrm{Na}$ arena onde ocorre o jogo que estamos analisando, observa-se a presença de diversos atores-jogadores, entre os quais: os artistas, a Igreja, a organização patrocinadora (Banco do Brasil), a organização realizadora (CCBB) e o poder público.

A seguir, analisamos os jogadores envolvidos e a dinâmica das relações que estabelecem; o jogo propriamente dito, identificando as lógicas de ação predominantes e a disputa que empreendem pela manutenção de sua posição; e os recursos de poder que dispõem.

O que está em disputa no jogo aqui tratado é a definição do sentido da arte. Para o Banco do Brasil, patrocinador da mostra e financiador do centro cultural que a promoveu, a arte serve como importante instrumento de comunicação. Por meio de estratégias de marketing, a organização agrega valor à sua marca, internalizando atributos do projeto cultural apoiado. Apesar de ser detentor de grande capital econômico, o Banco não possui muito capital cultural, o que o coloca em posição de instabilidade no campo. Para efeito de diminuir essa instabilidade e adquirir legitimidade, o Banco estabelece relações com a comunidade por meio da manutenção de centros culturais de apoio às artes. Essa ação está, na verdade, circunscrita por uma lógica econômica, uma vez que, por meio do aumento da legitimidade, visa atrair mais clientes, melhorar a performance e incrementar os negócios.

O Banco do Brasil alega que a retirada da obra de Márcia X foi provocada pelo excesso de reclamações por parte da sociedade. No entanto, a decisão parece ter sido tomada devido à queixa-crime contra os organizadores da mostra, registrada pela Opus Christi, no $1^{\circ}$ Distrito Policial do Rio de Janeiro. Na queixa, a organização alegou que a obra caracterizava uma "afronta à fé católica"4.

A Opus Christi é uma congregação apostólica que existe desde 1997. A entidade, segundo seu presidente, entra em ação sempre que alguém vai de encontro aos sentimentos da coletividade católica, fere os direitos humanos e da cida-

4 Jornal Folha de São Paulo, 20 abr. 2006, Cotidiano. 
dania ou atinge a moral e a ética do ser humano. Num primeiro momento, pode-se dizer que a organização é orientada por uma racionalidade substantiva, preocupada com a crença em valores.

Ao argumentar que a obra "Desenhando com Terços" feria sentimentos religiosos, a Opus Christi sacraliza a obra de arte, atribuindo a ela status de objeto de culto religioso, entrando, assim, como um ator-jogador, na disputa pela atribuição de sentido à arte. Em sua estratégia, a Opus Christi apropria-se do discurso da Igreja colocando-se no papel de sua representante. A Igreja possui posição privilegiada nessa arena por ser detentora de grande quantidade de capital cultural e econômico. Dessa forma, a Opus Christi torna-se, também, um jogador poderoso.

Para fazer pressão sobre o Banco, ao solicitar que todas as obras com símbolos católicos fossem retiradas da exposição no CCBB do Rio e de Brasília (para onde o evento iria na seqüência), a Opus Christi ameaçou convocar os católicos a boicotar o Banco do Brasil caso a mostra estivesse completa. ${ }^{5}$

Por trás da estratégia adotada pela Opus Christi, com o aval da Igreja, percebe-se a presença de dois discursos diferentes e contraditórios. Ao invés de recorrer aos valores que a congregação diz estarem sendo ameaçados pela presença da obra de Márcia X na exposição, ela pressiona o Banco utilizando-se da lógica econômica, qual seja, a do fechamento de diversas contas no Banco do Brasil.

Como resultado da pressão exercida pela Opus Christi, a direção do Banco do Brasil resolveu retirar a obra da exposição alegando "centenas de reclamações". Tal atitude desrespeita a autoridade legítima do curador ${ }^{6}$, que deveria ter a pertinência por qualquer alteração na narrativa da exposição em função de sua competência técnica, expressão de capital cultural. A decisão representou uma alteração na importância atribuída aos diferentes tipos de capital no campo.

A sobreposição das questões mercadológicas sobre a lógica inerente à subjetividade da ação cultural (aqui expressa na narrativa construída pelo curador), é fruto da política de incentivos fiscais que tem estimulado a associação entre organizações empresariais e instituições culturais. É esta política, associada ao crescimento da percepção de que estratégias de comunicação empresariais ligadas a projetos culturais, esportivos e sociais são mais eficientes, que estimulou a criação de fundações e centros culturais mantidos por outras organizações que não têm a promoção da cultura como atividade fim, como instituições bancárias e empresas de telecomunicação, por exemplo.

Nesse perfil se enquadra o CCBB, uma organização cultural mantida com recursos do Banco do Brasil, que são, em parte, subsidiados por leis de incentivo à cultura, as quais permitem o abatimento nos impostos devidos. Nessa forma de investimento, se estabelece uma parceria entre o Estado e o contribuinte, na qual - governo abre mão de parte da arrecadação para que o parceiro invista seus impostos em projetos culturais. É por meio desta relação que as fundações privadas, como o CCBB (além do Itaú Cultural e do Instituto Moreira Salles, por exemplo), se tornam importantes para as estratégias de comunicação das empresas investidoras, que vêem no desenvolvimento de políticas culturais privadas ou, simplesmente, na consecução de ações de marketing, boas oportunidades de comunicarem-se com seus públicos, além de agregar valor às suas marcas. Assim, observa-se que o capital cultural perde importância para o capital econômico na definição do sentido da arte.

Apesar do Centro Cultural agir sob uma lógica que, necessariamente, deve refletir a relação de produção e fomento à cultura (mais orientada pela racionalidade substantiva), ele é dependente dos recursos do banco que o patrocina e que se orienta pela lógica econômica. No caso analisado, por exemplo, a decisão da diretoria do Banco de retirar a obra da exposição, sobrepondo-se à direção do CCBB e

\footnotetext{
5 Jornal O Globo, 22 abr. 2006, p. 13.

${ }^{6}$ Em declaração à imprensa, o curador da exposição Tadeu Chiarelli disse que não foi sequer consultado sobre a questão. Fonte: Jornal O Globo, 21 de abril de 2006, p. 13.
} 
do curador, está totalmente fundada numa racionalidade instrumental, na qual se evidencia a ameaça de perda imediata de clientes.

Como justificativa, o Banco (e não o CCBB), em nota divulgada na imprensa, informou que retirou a peça após ter recebido mais de 700 e-mails com reclamações a respeito da obra "Desenhando com Terços". Ainda, argumentava que alguns clientes ameaçaram encerrar suas contas. Em entrevista ao site Canal Contemporâneo ${ }^{7}$, a assessoria de imprensa do Banco do Brasil alegou que foram consideradas, também, questões de imagem e aspectos empresariais. A função do diretor do CCBB Rio é colocada em questão nesse momento, uma vez que não houve nenhuma manifestação pública dessa instância de poder durante toda a polêmica. A decisão foi acatada silenciosamente pelo CCBB que, assim, teve evidenciada a sua fragilidade e sua subordinação na relação de poder com o Banco. Isto, mais uma vez, demonstra a perda de importância do capital cultural no campo, bem como a atribuição de um sentido específico à arte.

No outro lado da arena, encontram-se os artistas e o curador da mostra. Este declarou seu repúdio dizendo que ele e a produtora do evento foram surpreendidos pela decisão que considera unilateral e que "corta uma tradição de diálogo entre as partes" 8 .

A classe artística expressou sua indignação por meio de algumas manifestações públicas. Cerca de 30 artistas plásticos cariocas foram às ruas do Centro e ao Centro Cultural, em defesa da liberdade de expressão artística e cultural, em protesto contra a censura e indignados com a decisão do Banco do Brasil. Empunhavam cartazes e faixas que diziam "Abaixo a Censura". A manifestação se repetiu na semana seguinte, quando, em quantidade maior, portavam uma camiseta com a estampa da obra e os dizeres "Educa Ação/ Censura Não" e lançaram um abaixo-assinado que obteve 800 assinaturas (mais que o número de emails que o banco disse receber contra a manutenção da obra).

Artistas que participavam da mostra ameaçaram retirar suas obras. A artista Rosângela Rennó exigiu, em carta ao Diretor do CCBB, que suas peças expostas no evento do Rio fossem cobertas, e ameaçou retirá-las da exposição de Brasília, caso a obra de Márcia X não fosse reintegrada à mostra. As obras de Rosângela ocupavam uma sala especial (o cofre) e permaneceram tapadas, na última semana da exposição, com a carta fixada sobre o pano preto, transformando-se numa das mais eficazes ações de protesto.

O discurso vindo dos artistas, em protesto ao ocorrido, esteve pautado pela garantia à autonomia da obra de arte. O repúdio à censura e a defesa da liberdade de expressão e da livre interpretação mostram o quanto à lógica da arte pela arte está presente. Os artistas, como detentores de grande volume de capital cultural, sempre foram importantes formadores de opinião. No entanto, no episódio do CCBB Rio, o uso deste recurso de poder (que poderia prejudicar a imagem da organização patrocinadora) não foi suficiente em relação aos recursos usados pela Igreja. Os bispos da CNBB (Conferência Nacional dos Bispos do Brasil) telefonaram para diretores do Banco ameaçando incluir o debate sobre a obra nos seus sermões, e diversos grupos religiosos ameaçaram fechar contas e boicotar o Ban$\mathrm{CO}^{9}$. Como resultado, o CCBB não retornou a obra para a exposição do Rio e ainda cancelou o evento de Brasília.

O último ator a ser analisado é o Estado que, no caso analisado, esteve presente por meio dos instrumentos de política cultural que permitem a intervenção tão forte do patrocinador num projeto cultural e, também, como principal acionista do Banco do Brasil. Observa-se que a intervenção direta do Estado foi bastante tímida, restringindo-se à nota do Ministro da Cultura, em que repudia a censura, citando a Constituição Brasileira e dizendo esperar que o CCBB reconsiderasse a decisão ${ }^{10}$. Ao dirigir-se ao CCBB, o Ministro da Cultura vai ao encontro

\footnotetext{
${ }^{7}$ www.canalcontemporaneo.com.br.

8 Jornal O Globo, 21 abr. 2006, p. 28.

9 Folha On Line, 03 mai. 2006.

10 Globo On Line, 26 abr. 2006.
} 
do ator-jogador institucionalmente legitimado e, portanto, correto para decidir sobre o episódio, caso o jogo jogado fosse o oficial. Entretanto, vimos que há contradição em vários discursos utilizados no campo, particularmente o da Opus Christi. Esta atitude pode representar tanto o uso de uma imagem do jogo distante do real para fins de preservação da imagem, quanto um desconhecimento sobre as reais regras do jogo.

\section{O) Fim dlas Corntas dle rum Térȩo Polềnico}

Ao final do jogo, constatamos o imbricamento entre distintas motivações e lógicas de ação no campo da cultura.

No que concerne à relação entre a instituição empresarial e a organização cultural, percebemos que apesar da primeira se legitimar a partir do apoio às ações da segunda, busca mantê-la totalmente subjugada à sua lógica. Observamos que a fronteira entre essas duas organizações fica obscurecida, com a diretoria do Banco assumindo declarações e ações no lugar da direção do Centro Cultural.

Sobre o sentido da arte, constatamos que o banco desconsidera as decisões artístico-culturais que deveriam prevalecer sobre a narrativa da exposição e sobre o Centro Cultural. Espaço este que, para permitir a experiência artística, deveria requerer um afastamento da vida cotidiana e configurar-se como um espaço de estranhamento, um território livre e adequado para a complexidade do mundo contemporâneo. Chagas (2006) afirma que os museus se constituem enquanto campos de tensão e de contradição, espaços de produção simbólica e de transformação dos sentidos, "ponte entre tempos, espaços, indivíduos, grupos sociais e culturas diferentes (...)", lugares de memória e de esquecimento.

A lógica econômica é, também, a que prevalecerá nas ações adotadas pela Igreja para pressionar o Banco. Apesar de suas reivindicações se basearem em questões morais, os instrumentos de pressão são totalmente orientados pela instrumentalidade, num claro exemplo da transmutação do capital econômico em simbólico, que legitima a ação do grupo religioso. Tal legitimidade falta à classe artística, que não consegue o apoio da população para a sua causa. Esse fato, talvez, possa ser justificado pela lógica do campo da produção erudita que mantém uma relação de indiferença com o público não especializado, aceitando como legítimo somente o leitor ideal, que é um outro intelectual (BOURDIEU, 1968).

O cancelamento do evento no CCBB de Brasília pode ser visto como uma vitória parcial dos artistas, que ameaçaram retirar suas obras caso o trabalho de Márcia X não fosse reintegrado à exibição. Por falta de acordo, o Banco do Brasil preferiu não dar continuidade à exposição. No entanto, os artistas não conseguiram levar o CCBB a reavaliar sua posição. O Banco do Brasil também perdeu nesse jogo, uma vez que não pôde pôr em prática sua política de comunicação por meio da exposição em Brasília, apesar de todo investimento que já havia feito.

Finalmente, constatamos a fraqueza das instituições responsáveis pelas políticas públicas para a cultura. Sendo o Estado ator fundamental no campo, deveria ser responsável pela intermediação das disputas entre as diversas lógicas, garantindo o espaço tanto da lógica inerente ao processo de criação e de interação dos grupos criadores, quanto daquela presente no processo de produção e distribuição dos bens culturais. No entanto, percebemos um Estado que se manteve alheio a este embate, numa clara demonstração da predominância dos interesses econômicos sobre a lógica da ação pública. Apesar de o governo federal vir buscando ampliar as formas de financiamento à cultura para além do incentivo fiscal, observamos uma grande dificuldade para romper com a primazia do modelo vigente. Tal dificuldade se observa no esforço que tem feito para buscar uma melhor distribuição dos recursos incentivados através do alinhamento das políticas de comunicação das estatais (como a Petrobras e a Caixa Econômica, por exemplo) com as políticas culturais públicas. No entanto, trata-se de uma ação que somente tangencia o problema. Além disto, o governo tem sido alvo de críticas que apon- 
tam para a existência de um dirigismo do Estado na aprovação de projetos culturais por essas empresas públicas.

Seria papel do Estado laico possibilitar que a sociedade se manifestasse culturalmente em todas as suas formas. No caso CCBB, entretanto, o Estado é também gestor da instituição financeira que se subordinou à pressão da organização religiosa. Assim, acaba, mesmo que por omissão, dirigindo a criação para uma cultura oficial e, conforme afirma a filósofa Marilena Chauí (1989), colocando-se como produtor e tirando da sociedade o lugar onde a cultura efetivamente se realiza.

Referê̂ncias

ALVES, Patrícia. Justiça nega pedido para censurar outra obra em exposição no CCBB. O Globo, Rio de Janeiro, p. 13. 22 abr. 2006.

ANDRADE, Jackeline Amantino; SILVA, Ana B. N. Política cultural apropriada pela sociedade: o Sistema Nacional de Cultura como rede interorganizacional. IV ENCONTRO DE ESTUDOS ORGANIZACIONAIS, 2006, Porto Alegre. Anais... Rio de Janeiro: ANPAD, 2006. 1 CD-ROM.

ARENDT, Hannah. A condição humana. São Paulo: Ed. USP, 1981.

ARTISTAS protestam contra veto à obra erótica. O Globo, Rio de Janeiro, p. 28. 21 abr. 2006.

BANCO DO BRASIL - CULTURA (Brasil). Erótica - Os Sentidos na Arte. Disponível em: <http://www.bb.com.br/appbb/portal/bb/ctr/rj/evt/

EvtDet.jsp?Evento.codigo=22211>. Acesso em: 16 out. 2006.

BENEVIDES, C.; NERI, N. Artistas protestam no Centro. Jornal do Brasil, 21 abril, 2006. Caderno Cidade, p.8.

BENJAMIN, Walter. A obra de arte na época de sua reprodutibilidade técnica. In: LIMA, Luiz Costa (Org.). Teoria da cultura de massa. São Paulo: Paz e Terra, 2002. p. 221-254.

BOURDIEU, Pierre. Campo intelectual e projeto criador. In: BOURDIEU, P. et al. Problemas do estruturalismo. Rio de Janeiro: Zahar Editores, 1968. p.105-145.

. Gostos de classe e estilos de vida. In: ORTIZ, Renato (org.). Pierre Bourdieu: sociologia. São Paulo: Ática, 1983. p. 82-121. 1993.

. The field of cultural production. Great Bretain: Columbia University Press,

. Economia das trocas simbólicas. São Paulo: Perspectiva, 2001.

. Razões práticas: sobre a teoria da ação. Campinas: Papirus, 2004a.

. O poder simbólico. 7 ed. Rio de Janeiro: Bertrand Brasil, 2004b.

CANAL CONTEMPORÂNEO (Ed.). Banco do Brasil responde a três perguntas do Canal Contemporâneo. Disponível em: <www.canalcontemporaneo.com.br>. Acesso em: 08 maio 2006.

CARVALHO, Mário C. BB cancela a exposição "Erótica" em Brasília. Folha de São Paulo On Line, São Paulo, 03 mai. 2006. Disponível em: <www.folha.com.br>. Acesso em: 21 junho, 2006.

CHAGAS, Mário. Só a antropofagia nos une: o poder devorador dos museus. Revista Eletrônica do Patrimônio, 5, mai./ jun. 2006. disponível em: http:// www.revista.iphan.gov.br/ 
CHAUI, Marilena. Cultuar ou cultivar. Revista Teoria e Debate. São Paulo, Fundação Perseu Abramo, no. 08, out/nov/dez 1989.

COELHO, Teixeira. Dicionário crítico de política cultural: cultura e imaginário. São Paulo: Iluminuras, 2004.

FLEURY, Sonia. Reforma del Estado. RAP. Rio de Janeiro 35(5): 7-78, Set/Out. 2001.

FIGUEIREDO, Talita. Banco proíbe "terço erótico" em exposição. Folha de São Paulo, São Paulo, 20 abr. 2006. Cotidiano. Disponível em: <www.folha.com.br>. Acesso em: 08 maio 2006.

MATUS, Carlos. Chipanzé, Maquiavel e Ghandi: estratégias políticas. São Paulo: FUNDAP, 1996.

MENESES, Ulpiano Bezerra. O museu e o problema do conhecimento. Anais do IV Seminário sobre Museus-Casas. Rio de Janeiro: Fundação Casa de Rui Barbosa, 2002. p.17-41.

MIZOCZKY, Maria Ceci. O campo da atenção à saúde após a constituição de 1988: uma narrativa de sua produção social. Porto Alegre: Da Casa Editora, 2002.

MOUTINHO, Mário. Sobre o conceito de museologia social. In: Cadernos de Museologia. n.1, ULHT, 1993. p.5-6.

OLIVIERI, Cristiane G. Cultura neoliberal. São Paulo: Escrituras, 2004.

SANTOS, Myrian Sepúlveda dos. Museus brasileiros e política cultural. Revista Brasileira de Ciências Sociais, junho, 2004, vol. 19, número 055. Associação Nacional de Pós-Graduação e Pesquisa em Ciências Sociais. São Paulo, Brasil. p.53-72.

THIRY-CHERQUES, Hermano R. Pierre Bourdieu: a teoria na prática. Revista de Administração Pública (RAP). Rio de Janeiro, v.40, n.1, p.27-55, 2006.

VELASCO, Suzana. Ministro Gilberto Gil se manifesta contra censura à obra de Márcia X. O Globo On Line, Rio de Janeiro, 26 abr. 2006. Disponível em: <http:// oglobo.globo.com/online/>. Acesso em: 08 maio 2006.

YIN, Robert K. Estudo de caso: planejamento e métodos. São Paulo: Bookman, 2004. 